\title{
A HEURISTIC THEORY OF NEUROSIS *
}

BY

\section{ELIOT SLATER and PATRICK SLATER}

\author{
(RECEIVED 15TH MAY, 1944)
}

\begin{abstract}
Introduction
IN a recent communication (Slater, 1943), based on a statistical survey of two thousand neurotic soldiers, a hypothesis was developed to the effect that there was a generalized predisposition towards neurosis, which was in large part responsible for the appearance of neurotic symptoms in the individual when placed under stress. Evidence was adduced that this constitutional tendency, though it might be affected by such environmental factors as early processes of conditioning, was, at least in part, dependent on hereditary factors. Evidence was also brought that it could usefully be considered in a quantitative manner, and that so considered the intensity of the constitutional predisposition varied inversely with the degree of stress under which the individual was placed before breakdown occurred, i.e. the greater the intensity of the constitutional predisposition, the less was the degree of stress required to produce breakdown, and vice versa.
\end{abstract}

On this last point, strong confirmatory evidence has recently been supplied by Symonds (1943). He states " the incidence of neurosis in different tactical duties varies directly with the amount of hazard encountered, as measured by the casualty rates." $\mathrm{He}$ also provides a table correlating the degree of predisposition with the degree of stress in 2,200 neurotic casualties, which shows that the degree of flying stress falls steadily as predisposition increases. From his table a correlation coefficient between the two variables of $-0.26 \pm 0.02$ can be calculated.

In the paper referred to no very detailed analysis of the nature of the neurotic predisposition was undertaken. Yet the frequency of various traits of personality was shown to vary significantly in the several diagnostic groups, and significant and fairly high correlations were found between personality traits and eventual symptomatology. There was, therefore, evidence of constitutional heterogeneity in the population investigated. On the other hand all the neurotic personality traits were noted as being at least sometimes present in all the diagnostic groups, and the same was true of all the classes of symptoms observed, with the exception of obsessional compulsive symptoms and psychotic and organic symptoms. This means in effect that the

\footnotetext{
* Based on a paper read before the Genetical Society on $6 / 1 / 44$
}

different neurotic groups fade off into one another clinically, and do not form qualitatively distinct groups. This observation is one with which every clinician is in practice familiar.

This, then, is the starting point of the argument which is developed in the following pages. It is our purpose to reduce the hypothesis already propounded to precise terms which may be handled statistically, and made the basis of predictions which can be checked by further observations. What is involved is, in fact, a general theory of the nature of the neurotic constitution.

\section{Possible Theories}

The various theories which may be advanced to account for the phenomena of the neuroses seem capable of being divided into three classes. By the first of these, neurotic phenomena are regarded as a type of response to which all human beings are equally liable, such as, for instance, the general tendency to respond with fever to the occurrence of an infection. Differences between individuals would then be related solely, or at least to a preponderant extent, to environmental effects. This theory has been very commonly, even if implicitly, held in the past; but it has of late been found inadequate. If this were an adequate explanation of the phenomena we have to discuss we would expect, as indeed we find, that the intensity of the stress under which an individual was placed would be directly related to the frequency of nervous breakdown. But we would in addition expect to find a direct relationship, both qualitative and quantitative, between the type and intensity of the stress and the type and severity of the breakdown. This is true only to the most limited extent. In the survey referred to there was evidence that the terrifying stresses of war tended to provoke anxiety states to a significantly preferential extent, but they did so far from regularly. A more important determinant of the type of response was the constitution of the individual as shown by his family history, previous life, and personality. This theory, in fact, breaks down by not taking into account or explaining in any way the very large amount of evidence of the existence of constitutional differences between individuals in these respects, and especially of their genetic aspects. It would leave 
unexplained the results of investigations of personality differences and similarities in binovular and uniovular twins (Kranz, 1936; Lange, 1929; Newman, Freeman, and Holzinger, 1937; Stumpfl, 1936, etc.), and the evidence of the familial incidence of neuroses and psychopathy (von Baeyer, 1935; Berlit, 1931; Brown, 1942; Brugger, 1935; Curran and Mallinson, 1940; Gebbing, 1932; Kolle, 1932; Kraulis, 1931; Lewis, 1936; Pohlisch, 1934; Riedel, 1937; Ritter, 1937; Schröder, 1939; Slater, 1943 , etc.). In so far as early environmental differences might help to explain individual differences in disposition in later life, one would expect to find an association between the occurrence of neurosis and place in order of birth; the evidence is against this (Brown, 1942; Slater, E., 1944). This theory must be rejected.

The second theory that engages our attention is that the neurotic constitution is of a unitary kind, but dependent on genetic factors. It is possible to consider this theory in two forms. By the first, the genetic basis would lie in a single abnormal gene, whose variations in expression could be accounted for by environmental differences and by differences in genetic modifying factors, the so-called genotypic milieu. Theories of this type provide a sufficient account of the relevant data in such psychiatric conditions as phenylpyruvic amentia (Jervis, 1939), juvenile amaurotic idiocy (Sjögren, 1931; Jervis, 1941), gargoylism (Halperin and Curtis, 1942), oxycephaly (Ferriman, 1941), epiloia (Gunther and Penrose, 1935), Huntington's chorea (Sjögren, 1935), cerebral dysrhythmia and epilepsy (Lennox, Gibbs, and Gibbs, 1939, 1940, 1942), manic-depressive psychoses (Kallmann, 1941; Slater, 1936, 1938), schizophrenia (Kallmann, 1938; Kallmann, 1941; Koller, 1939; Lenz, 1937; Luxenburger, 1937; Patzig, 1937, etc.). In all these conditions findings are made which are believed to be specific for the condition in question; and it is worth remarking that similar investigations of neurosis and psychopathy have not resulted in comparable findings. On the basis of the theory, transitional forms between the normal and abnormal may occur, but will either be relatively infrequent, or will be capable of resolution with more refined examination into characterbearers and normals. Where this is only doubtful, as, for instance, in manic-depressive psychosis, some doubt is thrown on the postulation of a single gene. If a single abnormal gene were postulated as the basis of neurosis, necessary consequences would be that neurotics would prove to be relatively homogeneous, and would show some highly discriminant characteristic which would differentiate them with fair certainty from the average population. As will later be shown, the evidence is against homogeneity, and no single discriminant characteristic has so far been discovered.

The alternative form of the second theory is that the neurotic predisposition, though still regarded as unitary, is dependent on a large number of separate genes of small but similar effect. This postulation would allow us to explain quantitative variation in the intensity of the neurotic predisposition, and would also permit the inclusion of neurotics within the limits of range of the general population. The outstanding example of a finding which is accounted for in this way is the distribution of intelligence in the general population. Fraser Roberts (1939), describing the situation, writes:

"General intelligence, in this sense, is a graded character and displays continuous variation from one extreme to the other... Over the great bulk of the range there is no discontinuity ... A frequency curve is found to conform to the normal form. But at the extreme ends of the distribution, most certainly at one end, we find variations which are no longer continuous, and the curve is no longer normal ... Without discontinuity anywhere we pass from the brilliant to the superior, the average, the dull, the very backward, and finally to the mentally defective. At the very lowest levels, however, we find not merely the very backward; we find gross deviations, the idiots, and the imbeciles . . This portion of the curve is far from normal, for such individuals are far too numerous. The distinction, on the basis of measurement only, is not absolute . . . (but) is fundamental genetically .... We have, on the one hand, multifactor inheritance, on the other hand, the transmission of single genes; on the one hand, the genes of individually small effect, on the other, the gene whose bearer is sharply distinguished from the rest of his fellows . . . It is not impossible to mark approximately the line of division between the two types of mental defective. On the Binet scale it may be drawn roughly at an I.Q. of about 45 . . . Feeble-minded persons must be regarded as abnormal, but this is probably true only against the background of our present complex civilization. They are merely the extreme minus end of the normal distribution of intelligence."

This theory is still capable of explaining all the important genetic data on mental defect, and long occupied a prominent position in the field of psychometric psychology. Spearman and Hart (1912) put forward the view that all mental processes belonged to a single class, and that the interrelations of all tests used to measure them could be accounted for in terms of a single common factor, $g$. More recently, however, this theory has been shown to be inadequate, and even when only cognitive tests are used, most tables of results indicate the operation of more than one common factor. A continuous variation from brilliance to defect is found in adequately measurable cognitive abilities other than intelligence (such as spatial judgment), and frequency distributions are of the normal form. Methods of assessing variations in temperamental characteristics have not been carried far enough at present to provide critical evidence, but there is no reason to suppose that the frequency distributions depart from normal. Thus the distribution of psychological characteristics is currently supposed to be of the multivariate normal form.

A necessary consequence of the unitary theory is the homogeneity of selected samples. If adding and subtracting depend on the same ability, men who add equally well are not likely to differ greatly in ability to subtract. Similarly if the neurotic predisposition is a unitary trait, variations in characteristics which differentiate neurotics from normals will 
be smaller among neurotics, who form a selected sample, than among an unselected normal population. The presence or absence of homogeneity among neurotic subjects is therefore a matter of crucial importance; if it fails to hold, as Roberts points out is the case in the lowest reaches of mental defect, the theory breaks down, and supplementary hypotheses have to be made.

But the heterogeneity of the neuroses is, actually, a commonplace of clinical experience. If it did not exist, we should not be tempted to diagnose one man as a hysteric, another as an anxiety neurotic, and a third as a depressive. In respect of purely qualitative findings the statistics already provided (Slater, 1943) may be relied on. Further data of a quantitative and therefore more precise kind will be adduced later on. It is sufficient to state here that the evidence on this point is, in our opinion, sufficient to render the unitary hypothesis of the neurotic constitution unlikely and not suitable for use as a weapon of research.

We come, therefore, to the third of the possible hypotheses of the nature of the neurotic constitution. By this theory the constitutional basis of neurosis is still held to be, in part at least, genetic in nature, but due to the operation of factors not all of similar effect. This theory again may be presented in two forms. In the first of these the several genetic factors would be supposed to be each in itself sufficient, at least under suitable environmental circumstances, for the production of a neurosis, the type of the neurosis depending on the gene responsible.

Neurosis would then become a congeries of qualitatively distinct syndromes. With adequate knowledge of the differentiæ of neurotics, we would be able to sort them out from the remainder of the population, who would be immune to neurosis; we would also be able to sort out the neurotics into their various classes. In the family histories of neurotics, we would expect to find that the specific forms of neurosis characteristic of the propositi occur with exceptional frequency, but that other forms of neurosis occur with no greater frequency than in the general population. We would also expect that the frequency with which neurotic abnormalities occur would bear no necessary relation to the extent to which these abnormalities deviate from the norms of the general population. The available evidence is against these expectations. Persistent search for characteristics which will clearly discriminate between different types of neurotics and between them and normals has so far proved fruitless. Not only specific, but also non-specific forms of neurosis are commoner among the relatives of neurotic propositi than in a control group. To substantiate this last point we may quote the evidence provided by Brown (1942).

This observer investigated the frequency of various types of psychiatric abnormality among the parents and sibs over the age of fifteen of different groups of neurotic propositi. From the data provided by him the following table can be constructed:

\begin{tabular}{|c|c|c|c|c|}
\hline \multirow{2}{*}{ Numbers of } & \multicolumn{4}{|c|}{ Among Parents and Sibs of } \\
\hline & $\begin{array}{c}\text { Anxiety } \\
\text { Neuro- } \\
\text { tics }\end{array}$ & Hysterics & $\begin{array}{l}\text { Obses- } \\
\text { sionals }\end{array}$ & Controls \\
\hline 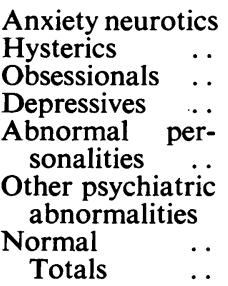 & $\begin{array}{r}55 \\
7 \\
2 \\
9 \\
\\
60\end{array}$ & $\begin{array}{r}7 \\
12 \\
-\end{array}$ & $\begin{array}{r}3 \\
7 \\
4\end{array}$ & $\begin{array}{c}\overline{2} \\
-\end{array}$ \\
\hline
\end{tabular}

We may observe, among the relatives of the three groups of propositi, the incidence of the non-specific anomalies, i.e. everything but anxiety neurosis among the relatives of the anxiety neurotics, everything but hysteria among the relatives of the hysterics, etc., and compare them with the corresponding incidences in the control group. In this way we obtain the following figures:

\begin{tabular}{l|c|c|c}
\hline & $X^{2}$ & $\begin{array}{c}\text { Degrees } \\
\text { of freedom }\end{array}$ & $\begin{array}{c}\text { Proba- } \\
\text { bility }\end{array}$ \\
\hline $\begin{array}{l}\text { Anxiety group _.. } \\
\text { Hysterical group .. }\end{array}$ & $\begin{array}{l}26 \cdot 363 \\
22 \cdot 249\end{array}$ & 5 & $<\cdot 01$ \\
$\begin{array}{l}\text { Obsessional group } \\
\text { Totals }\end{array}$ & $\begin{array}{c}30 \cdot 418 \\
79 \cdot 030\end{array}$ & 5 & $<\cdot 01$ \\
& 13 & $<\cdot 01$ \\
& & $<\cdot 01$ \\
\hline
\end{tabular}

In other words it may be asserted with a high degree of certainty that the relatives of all three neurotic groups of propositi distinguish themselves from normals by an excessive liability to other psychiatric abnormalities than the specific ones in question.

We are therefore led to consider an alternative form of the third hypothesis. According to this, the genetic determinants which produce a neurotic constitution are generally non-specific and additive in their effects. Each operates to produce a reduced resistance to some kind of stress; and in their endless combinations, they facilitate the occurrence of a wide variety of neurotic states, in which phenomena symptomatic of one type of diagnosis may overlap with those symptomatic of others. This theory again leads to a number of expectations, which can be compared with observed facts.

In summary, theories of neurosis seem capable of being classified in three main categories:-

(i) Those which imply that the causes of neurosis are wholly exogenous.

(ii) Those which postulate a unitary endogenous factor determining variations in susceptibility to neurosis; it may be either:

(a) A single abnormal gene.

(b) A large number of separate genes of small but similar effect.

(iii) Those which assume more than one genetic factor, with dissimilar effects, to account for the neurotic constitution. They may either:

(a) be specific to a particular type of neurosis;

(b) overlap in their effects and produce predispositions to more than one type of neurosis. 
Many of the phenomena of neurosis are compatible with more than one of these hypotheses, and may be observed without provoking any explicit choice (though a choice is often involved by implication in the interpretation placed on neurotic phenomena). There may be advantages, however, in choosing a particularly promising hypothesis, even before it can be claimed to be the only possible one, and seeing where it leads us. The one we have chosen belongs to class (iii) (b). A general and a precise formulation follow, together with evidence to explain our choice.

\section{The Proposed Theory}

A very large number of characteristics may be differentiated among men, each of which plays a part in determining the success with which the individual adapts to circumstances. We can define each of these characteristics in such a way that the possession of it promotes success and lack of it promotes failure. In these terms our theory is that the normal man possesses certain characteristics and lacks others in roughly equal proportions; the man with neurotic tendencies, on the other hand, lacks many and possesses few. Although he may not be found abnormally lacking in any particular characteristic, the consequence of his being lacking in many is that he is more than averagely prone to be unsuccessful in his adaptations, and to relapse in consequence into neurotic symptoms. Thus a man with neurotic tendencies may be no more lacking in characteristic $\mathrm{A}$ than many men whose adjustments are normal; but he may also lack characteristics $B$, $\mathrm{C}, \mathrm{D}$, and $\mathrm{E}$, of which men who lack A normally lack only one or two. Another man with neurotic tendencies may not be lacking in A or B, but may lack C, D, E, and F. Thus, although he falls into the same broad class, of men prone to neurosis, his personality may present a different picture, and the conditions which induce him to break down and the symptoms he then develops may all be different.

In more precise terms, every individual possesses characteristics variable in strength which render him more or less liable to a neurosis of any kind. Whether he succumbs to a neurosis of a particular kind or not depends on the extent to which he is endowed with characteristics which help to confer immunity to that kind of neurosis, and on the nature and the degree of the stresses to which he is exposed. We do not wish to suggest that all these characteristics are entirely endogenous or genetically determined.

In the general population each of these characteristics may be considered as normally distributed, so that their collective distribution may be visualized as a normal surface in many dimensions. This multivariate frequency ellipsoid is exposed to a series of stresses of different degrees coming from different directions, which have the effect of partitioning it in various ways. Each particular stress divides the population into two classes- those who withstand it and those who succumb. The apparent qualitative distinction between neurotics and normals is the resultant of a balance between two quantitatively variable forces. When stress exceeds resistance, the man becomes classifiable as neurotic, when resistance exceeds stress, as normal. Both stress and resistance vary in degree.

But both vary also in kind. Some people may be so feebly endowed in all relevant characteristics that they may succumb to almost any stress, provided it is sufficient in degree. A particular stress, if sufficient, will produce symptoms of neurosis in these people, but may also find out the Achilles heel in others who would have been immune to any equally severe stress coming from a different direction.

We present this as a heuristic hypothesis, i.e. not as one which can be either finally proved or disproved on existing or readily accessible evidence, but as one which may prove useful for experimental purposes. Any satisfactory theory of neurosis is more likely to be reached rapidly and established soundly, we believe, if the implications of the proposed theory are explored than if they are ignored.

Why is it likely to be useful? Arising from genetic considerations, it offers an account of the relationship between normal and abnormal psychological phenomena and therefore extends the range of observations which students of either branch of psychology can take into account. In particular it relates the problems of psychiatry to the general concept of human variability which has been developed by psychometric psychology, and which again is related to the system of applied logic which has been found suitable for the biometric sciences as a whole. It therefore places at the disposal of psychiatry the scientific techniques, particularly those of statistical analysis which have been developed for the biometric sciences by Galton, Pearson, Fisher, and others. These practical advantages are sufficient, in our opinion, to justify asking for a trial of the theory.

Some of its corollaries may be suggested as suitable for study:

1. (Also reconcilable with theories of types (i) and (ii) (b).) Neurotics, by hypothesis, are obtained from the normal population by a process of selective sampling, and are therefore a sub-class of normal men. If so, in the observation of any particular characteristic, neurotics will be found to fall within the limits of range of the general population, and will not occur in excessive numbers at a particular extreme.

2. (Also reconcilable with types (i) and (ii) (b).) When unselected groups are submitted to environmental stress of varying degrees, the numbers of persons breaking down will increase with the intensity of the stress, and no final end-point will be found at which all have broken down who are ever liable to. The relationship between degree of stress and frequency of breakdown will be positive, but of limited extent because:

3. (Also reconcilable with (iii) $(a)$.) Certain types of stress will be particularly likely to produce breakdown among particular types of people, e.g. acute physical danger and uncertainty among persons liable to anxiety states, positions of grave responsibility among those of obsessional types, etc. This relationship will also be limited in extent, since people are affected by the degree of a given stress as well as the direction from which it comes.

4. Conversely, it should be possible to assess the liability of different individuals to neurosis generally and to neuroses of different kinds specifically. Those who break down under the least degrees of stress should be found the most heavily loaded with "negative" characteristics, as earlier defined.

5. (Also reconcilable with type (i).) Mixtures of characteristics, and therefore mixtures of symptoms, will occur more frequently among neurotics than pure types.

6 . (Also reconcilable with (iii) $(a)$.) Neurotics will be found heterogeneous.

7. Among relatives of propositi suffering from a given type of neurosis, the incidence of neuroses of other kinds should be higher than among the normal population. 
If satisfactory evidence can be adduced on all these points, we shall consider our theory confirmed, since, taken together, they are irreconcilable with a theory of any other type than (iii) (b).

\section{Evidence Relevant to the Choice between Possible Theories}

Evidence has already been quoted from other sources in the discussion of possible theories above, which is sufficient, for instance, to exclude theories of type (i); and other evidence published by Slater (1943) corroborates every expectation listed above except 1 , on which no data were available. Other sources might be cited. But investigations conducted at Sutton Emergency Hospital during 1942-44 provide fresh unpublished evidence which is presented and discussed below.

In one experiment, six tests used by the Army for selecting personnel were given to enough serial weekly intakes at the hospital to provide a sample of 200 men: four were tests of mental abilities (general intelligence, verbal, arithmetic, and mechanical abilities) and two of physical abilities (agility and auditory acuity). The patients proved to have the same average age as men in the serving army, and reached the same average scores on the tests of mental abilities. Their agility was found to be lower and their auditory acuity poorer. The correlation between their results on these two tests is +0.3307 , which is significantly higher than the corresponding correlation in the normal serving army, $+0 \cdot 1004$ (on 2,600 cases).

Several hypotheses might account for these findings, among them the hypothesis that neurotics tend to be constitutionally inferior. This belongs to type (ii) $(b)$ : the fact that neurotics' agility is relatively poor is related hypothetically to the fact that their auditory acuity is also relatively poor, and a general common cause is supposed. If there is one, it should produce other effects, and appear, for instance, in other physical abilities. This was tested. The next $\mathbf{2 0 0}$ men in following intakes were given a test of visual acuity. They proved to have significantly poorer vision than men tested in the serving army, and significantly more of them wore glasses.

The hypothesis therefore appeared confirmed. It also agreed with previous results (Slater, 1943) which showed by factor analysis that positive family history, childhood neurosis, poor work record, previous nervous breakdown and abnormal personality are all interrelated phenomena among neurotics, and that their interrelations can be accounted for as manifestations of a common underlying characteristic, the neurotic constitution.

But there is nothing in this evidence which excludes our proposed theory. If we take a random sample of the population, we shall expect not only to find some men deficient in auditory acuity, but also, among these, some who are deficient in agility, and finally, among these, some who are also deficient in visual acuity. Our theory, in this instance, is simply that those who happen to be deficient in two or three abilities are those most likely to find their way into a neurosis centre. This accounts for the observations as adequately as the hypothesis of a single common factor.

There is, moreover, a point at which the evidence accords only apparently with the single factor theory, and in fact conflicts with it; and where the consideration of our theory provokes a closer inspection of the evidence and reveals the importance of facts which might have been overlooked. This contradictory evidence is that the correlation between the auditory acuity and agility tests is higher among neurotics than among normals. If both defects are manifestations of a neurotic constitution, and this is a unitary trait, the neurotics, who are alike in respect of it, should also be relatively homogeneous as regards the defects. But homogeneity lowers the correlation between associated variables (Thomson, 1939); so the proportions of the two correlations should have been reversed.

This leads us to compare variances in performance on the two tests among neurotics and normals. The mean square variance on the agility test is 4.39 times as great among neurotics as among normals $(5,000$ cases), and on the auditory acuity test at least $1 \cdot 19$ times as great $(2,600$ cases: but this test is not so sensitive to degrees of acuity above average as below). Although neurotics are supposed alike as regards neurotic constitution, and this is supposed to affect their test results on both tests, they are found, in fact, abnormally heterogeneous. When the correlation between their results is corrected for heterogeneity (Thomson, 1939), it is reduced to $+0 \cdot 1676$, which does not differ significantly from the normal value. Further corroboration is provided by the visual acuity test, on which the mean square variance of neurotics is 3.03 times that of normals $(2,233$ cases $){ }^{1}$

These observations suggested that further evidence on heterogeneity might be found if sought for. Qualitative findings differ in frequency among the different classes, as already shown (Slater, 1943); but heterogeneity can also be demonstrated quantitatively. The alphabetically arranged card index of the admissions to all military neurotic wards of the Hospital from the beginning of the war until January, 1944, were searched for persons with a diagnosis, or part diagnosis, of obsessional state: 113 of these were found. The next card lying to that of each of these was taken for a miscellaneous group, and the succeeding cards were searched for the nearest name with a diagnosis of anxiety state, hysteria, and reactive depressive state. Five groups, each of 113 persons, were so obtained by a strict method of random selection, and the relevant data are:

\begin{tabular}{lllll}
\multicolumn{1}{c}{ Diagnostic group } & & \multicolumn{2}{c}{ Mean age in years } \\
Obsessionals .. & $\ldots$ & $\ldots$ & 28.64 \\
Miscellaneous .. & $\ldots$ & $\ldots$ & $29 \cdot 25$ \\
Anxiety neurotics & $\ldots$ & $\ldots$ & 29.07 \\
Hysterics & $\ldots$ & $\ldots$ & $28 \cdot 89$ \\
Reactive depressives & $\ldots$ & $\ldots$ & 31.69
\end{tabular}

* Full particulars are on record at the War Office. 
The reactive depressives appear older than the others. A precise test shows that the difference is significant:

\begin{tabular}{c|c|c|c}
\hline $\begin{array}{c}\text { Source of } \\
\text { variance }\end{array}$ & $\begin{array}{c}\text { Sum of } \\
\text { squares }\end{array}$ & $\begin{array}{c}\text { Degrees } \\
\text { of fre edom }\end{array}$ & $\begin{array}{c}\text { Mean } \\
\text { square }\end{array}$ \\
\cline { 1 - 1 } Total variance in age & 25506.21 & 564 & - \\
$\begin{array}{c}\text { Variance between } \\
\text { depressives and } \\
\text { others . . . }\end{array}$ & 672.66 & 1 & $672.660^{1}$ \\
$\begin{array}{c}\text { Remaining variance } \\
\text { between groups }\end{array}$ & 23.05 & 3 & 7.683 \\
$\begin{array}{c}\text { Variance within } \\
\text { groups (error).. }\end{array}$ & 24810.50 & 560 & 44.304 \\
\hline
\end{tabular}

${ }^{1} \mathrm{~F}=15.183 \quad \mathrm{P}<0.01$

Note. - S.D. of age within groups $=$ root mean square variance $=6.656$ years.

The remaining groups do not differ significantly from one another, nor, for that matter, from the larger group of which they form a sample.

Scores of many of these patients on intelligence tests are kept, and were inspected for evidence of heterogeneity: the same procedure was followed. Different tests were in use at different periods. Records were sufficient to enable 300 patients to be classified in 12 groups of 25 according to diagnosis and test given. The diagnoses were the first four given above, and the tests used, Progressive Matrices, Shipley Vocabulary, and Cattell Intelligence Tests II, $a$. They show that obsessionals score significantly higher on intelligence than others, but that anxiety neurotics and hysterics do not differ significantly from each other or from the miscellaneous group (Slater, P., 1944).

Other data collected at the hospital by Miss E. Bennett, but not yet published, show that psychopaths are heterogeneous in their reaction times under free-association tests $(2,400$ times recorded).

Thus when age is considered, the heterogeneity of neurotics is demonstrated by the difference between reactive depressives and others; when intelligence is considered, heterogeneity is demonstrated by the difference between obsessionals and others; and heterogeneity is found among psychopaths when reaction times are measured. The accumulation of evidence demonstrating the heterogeneity of neurotics is considerable, and might be held sufficient to exclude theories of type (i) or (ii).

Evidence of a different kind is required to differentiate between theories of type (iii) $(a)$ and (iii) $(b)$. If the former is correct, neurotics must be treated as qualitatively distinct from normals; this would become necessary if it could be shown that some characteristics are present among neurotics which are entirely absent among normals, or that the absolute frequency with which abnormal degrees of certain characteristics occur among neurotics is too great to be treated as a random deviation from norms appropriate to the general population.

It is therefore important to arrive at the best possible estimate of the incidence of neurosis under the circumstances with which we have to deal at present. From the most complete information available, we estimate that the odds are about
65:1 against a man being referred to hospital for the treatment of a neurosis during a year's service in the army.

Let us apply this estimate to another criterion of neurotic tendency. In an experiment carried out by Miss Elizabeth Bennett at Sutton Emergency Hospital, lists were prepared of 100 things men might disapprove of, 100 that might make them nervous or afraid, and 100 that they might enjoy. This is an adaptation of the Pressey Cross-Out Test. It was given to 80 normal men and to 160 patients from the neurotic wards, of whom 80 were classified as neurotic and 80 as psychopathic. It was found that neurotics and psychopaths alike tended to disapprove of more, to be afraid of more, and to enjoy fewer things than the normals. An analysis of the answers suggests that the test functions as a measure of inadequacy. When the separate sections are appropriately weighted, neurotics and psychopaths tend to obtain negative scores, and normals positive ones. The overlap between the two groups is 26 per cent. We can estimate that the correlation between test result and neurotic tendency is +0.5 , and this is about as high as we can expect to obtain with any single test.

How much use is such a test as a diagnostic instrument? If neurotics and normals were two divergent types, and occurred in equal numbers, like males and females, we could differentiate them from each other correctly in 74 per cent. of our cases. But we have estimated that the odds against an unknown man developing a neurosis within a year are $65: 1$. So even if his score is an unusual one for a normal man, and a common one for a neurotic, the odds may still be in favour of his being normal, at least for an operationally effective period. In point of fact, if a man obtains the average score for a neurotic, the odds against his developing a neurosis are 13:1. Even if his score is so low that only 1 per cent. of neurotics score lower, the odds are only even that he will develop a neurosis within a year. The whole neurotic group falls within the normal group (i.e. those in an apparently normal state at a given time), when we take into account the relative sizes of the two groups.

As another instance, we might consider the use of the electroencephalogram as an index of abnormality. This test is ordinarily used to supplement a diagnostic opinion which carries its own independent weight. In treating the evidence of the test in isolation, we do not wish to be taken as implying any criticism of diagnostic opinions it has been used to supplement. In the average population the incidence of abnormality of E.E.G. is believed, on estimates available, to be approximately 10 per cent. In various types of the psychiatrically abnormal this frequency rises to any figure up to 90 per cent.; for a general neurotic group it has been given as approximately 25 per cent. Then if one man in 66 is liable to neurosis within a year, one in 79 of those with normal E.E.Gs. is so liable, and one in 26 of those with abnormal E.E.Gs. Let us, however, take a much larger estimate of the frequency of 
"neurosis." It has been suggested that about 10 per cent. of the population exhibit neurotic or psychopathic traits (that they exhibit them in some degree is readily admissible on our hypothesis). Then of those with normal E.E.Gs. one in twelve will be neurotic, and of those with abnormal E.E.Gs. one in four. In this case, as in the foregoing, one of a psychological test, the range of the neurotic group falls within the range of the normal, and no clear-cut qualitative distinction appears.

This evidence is only sufficient to illustrate the difficulties that are likely to be encountered in attempting to establish a theory of type (iii) (a), and the necessity of carrying out adequate control experiments among normals before any criteria are accepted as valid for differentiating neurotics. Ideally, if a theory of type (iii) (a) can be established, an exact classification of cases should be possible, into normals and neurotics of different varieties. If we prefer a theory of type (iii) $(b)$, we are not obliged to suppose that neurotics cannot be differentiated from normals or from one another. But our approach to this problem and our method of formulating conclusions will be different. By selecting a fairly large number of characteristics for measurement which are relatively independent of one another and which are more noticeable among neurotics than normals, and applying methods of weighted summation (e.g. by computing discriminant functions) we may be able to measure the probability that an individual may develop a neurosis, and grade people for relative liability or immunity (which may approach certainty of one kind or another in certain cases). Our main reason for preferring a theory of this type is that we believe it provides the more promising approach at the present time. A weighted summation of ten tests tried out by Miss Bennett, including the three sections of the adapted Pressey $\mathrm{X}-\mathrm{O}$ test already mentioned, provides a range of scores on which the probability of neurosis rises from less than 0.001 to over 0.99 (taking into account the estimate of the incidence of neurosis already given). Up to 20 per cent. of the population can be classed in the former category; while a bottom $2 \cdot 2$ per cent. can be differentiated, amongst whom 61.4 per cent. of the neuroses can be expected to occur.* The interpretation of observations according to our theory has therefore led to promising results.

\section{Summary}

Possible theories of the nature of the neurotic constitution are considered, together with their consequences in statistical expectations of various kinds. A theory is proposed, which is held to accord best with the relevant data available at present, and which has heuristic value in providing a scheme of attack on the genetic problems of psychopathy, and in rendering available to psychiatry the techniques of statistical analysis which have been found suitable to the biometric sciences. According to this theory, the neurotic constitution is pre-

* Results from 80 normal and 80 neurotic patients. A report on this experiment is being prepared for publication. ponderantly determined by a very large number of genes of small effect. The effects of these genes, at least in so far as they are qualitatively similar, may be additive; and they become manifest by producing a reduced resistance to some form of environmental stress, and so facilitate the appearance of a neurosis. In so far as the effects of the genes are qualitatively dissimilar, the type of stress effective in producing breakdown, and the neurotic symptoms produced, will tend to differ. The neurotically predisposed man is then to be regarded as a man who has a more than average susceptibility to environmental stresses of one or a number of kinds; he represents one of the extremes of normal human variation.

\section{REFERENCES}

Berlit, B. (1931). Z. ges. Neurol. Psychiat., 134, 382. Brown, F. W. (1942). Proc. roy. Soc. Med., 35, 785, Brugger, C. (1935). Z. ges. Neurol. Psychiat., 154, 223. Curran, R. D., and Mallinson, P. (1940). Lancet, ii. 738. Ferriman, D. (1941). Proc. Seventh Internat. Genet. Congr. (1939), 120. Cambridge.

Gebbing, M. (1932). Dtsch. Z. Nervenheilk., 125, 45.

Gunther, M., and Penrose, L. S. (1935). J. Genet., 31, 413. Halperin, S. L., and Curtis, G. M. (1942). Amer. J. ment. Defic., 46, 298.

(1939). J. ment. Sci., 85, 719.

Jervis, G. A. (1941). Amer. J. Dis. Child., 61, 327.

Kallmann, F. J. (1938). The Genetics of Schizophrenia. New York.

- (1941). New York State med. J., 41, 1352.

Kolle, K. (1932). Mschr. Psychiat. Neurol., 83, 127,

Koller, S. (1939). $\quad$ Z. ges. Neurol. Psychiat., 164, 199.

Kranz, H.(1936). Lebensschicksale krimineller Zwillinge. Berlin.

Kraulis, W. (1931). Z. ges. Neurol. Psychiat., 136, 174.

Lange, J. (1929). Verbrechen als Schicksal; Studien an kriminellen Zwillingen. Leipzig.

Lennox, W. G., Gibbs, E. L., and Gibbs, F. A. (1939). J. Amer. med. Assoc., 113, 1002.

Idem (1940). Arch. Neurol. Psychiat., 44, 1155. (1942). Ibid., 47, 702.

Lenz, J. (1937). Z. indukt. Abstamm., 73, 559.

Lewis, A. J. (1936). Proc. roy. Soc. Med., 29, 325.

Luxenburger, H. (1937). Z indukt. Abstamm., 73, 565.

Patzig, B. (1937). Zbl. ges. Neurol. Psychiat., 87, 707.

Newman, H. H., Freeman, F. N., and Holzinger, K. J. (1937). Twins: $A$ Study of Heredity and Environment. Chicago.

Pohlisch, K.(1934). Die Kinder männlicher und weiblicher Morphinisten. Leipzig.

Riedel, H. (1937). Z. ges. Neurol. Psychiat., 159, 597.

Ritter, R. (1937). Ein Menschenschlag. Erbärztliche und erbgeschichtliche Untersuchungen über die-durch siebzehn Geschlechterfolgen erforschten-Nachkommen von "Vagabunden, Jaunern und Räubern." Leipzig.

Roberts, J. A. F. (1941). Proc. Seventh Internat. Genet. Congr. (1939), $249 . \quad$ Cambridge.

Schröder, H. (1939). Allg. Z. Psychiat., 112, 224.

(1935). Z. mensch. Vererb: Konstitsl., 19, 131.

Sjögren, T. (1931). Hereditas Lund, 14, 197.

Slater, E. (1936). Proc. roy. Soc. Med., 29, 981. (1938). Z. ges. Neurol. Psychiat., 163, 1.

(1943). J. Neurol. Psychiat., 6, 1.

(1944). Ann. Eugen.
Slater, P. (1944). Brit.J.Psychol. Awaiting publication.

Spearman, C. and Hart B. (1912). Ibid., 5, 51.

Stumpfl, F. (1936). Die Urspringe des Verbrechens, dargestellt am Lebenslauf von Zwillingen. Leipzig.

Symonds, C. P. (1943). Brit. med. J., ii, 703.

Thomson, G. H. (1939): Factorial Analysis of Human Ability. London.

Von Baeyer, W. (1935). Zur Genealogie psychopathischer Schwindler und Lügner. Leipzig. 